\title{
FRACTIONAL COINTEGRATION RELATIONSHIP BETWEEN OIL PRICES AND STOCK MARKETS: AN EMPIRICAL ANALYSIS FROM G7 COUNTRIES
}

\author{
Burcu Kiran*
}

\begin{abstract}
:
This paper examines the long-run relationship between oil prices and stock market prices of G7 countries by using Robinson (1994a) tests for fractional integration and cointegration instead of the classical approaches. Having found that the unit root null hypothesis cannot be rejected for any individual series, it is examined whether oil prices and stock market prices have a fractional cointegration relationship. Test results on the residuals from the cointegrating regressions indicate that there is evidence of fractional cointegration between oil prices and DAX 30, Dow Jones, FTSE 100 and SP-TSX indices while there is no evidence of fractional cointegration for others.
\end{abstract}

Keywords: fractional integration, fractional cointegration, oil prices, stock markets, G7 countries.

JEL Classification: C10, E44, G15.

\section{Introduction}

Oil plays an important role in most economies around the world as a major source of inputs for a variety of petrochemical products (Happe, 1984). The simple demand and supply rule is valid for oil price, whereas it results from a perception of the equilibrium between the oil demand and supply. Although this perception is important, there are other external factors such as an increase of the oil demand from emerging countries, multiplication of tensions with Iraq and Iran and the recent interaction between oil and financial markets, which cause sharp increases (Jawadi and Leoni, 2009). If the oil price increases, this acts as an inflation tax on consumers and producers, while following two things happen (Basher and Sadorsky, 2006):

- consumers try to spend on other goods and services,

- oil price volatility increases risk and uncertainty, which negatively affects the stock prices and reduces wealth and investment.

Various transmission channels exist through which oil prices may have an impact on economic activity (Brown and Yücel, 2002; Jones et al., 2004; Lardic and Mignon, 2006). The relationship between oil prices and GDP can be understood via the classic

* Burcu Kiran, Istanbul University, Faculty of Economics, Beyazit, Istanbul, Turkey (burcukiran@ gmail.com).

The author would like to thank Associated Professor Mehmet Balc1lar for kindly providing the Gauss program codes. 
supply side effect. Oil price increases have a negative impact on output. An increase in oil prices leads to an increase in the cost of production which in turn causes a decrease in growth of output and productivity. Oil price increase represents an inflationary shock. As oil prices increase, the amount of money demand also increases. According to money demand increase, the inflation rate of the country may rise, investments may decrease and total GDP may decline. An oil price increase may have a negative effect on consumption, unemployment and trade of oil importer countries. In addition to these effects, oil price movements may also have an impact on stock prices.

While there is a huge literature concerning the relationship between oil prices and macroeconomic variables, there is relatively little work on the relationship between oil prices and stock markets prices. Huang et al. (1996) examine the link between daily oil future returns and daily United States stock returns. Their findings indicate that oil future returns do lead some individual oil company stock returns but they do not have much impact on general market indices. Jones and Kaul (1996) use quarterly data to test whether the reaction of international stock markets to oil shocks can be justified by current and future changes in real cash flows and/or changes in expected returns. Their results indicate that the reaction of Canadian and US stock prices to oil price shocks can be completely accounted for by the impact of these shocks on real cash flows. In contrast, the findings for Japan and the UK are not as strong. Jones and Gautam (1996) investigate the stock market of US, Canada, Japan and England based on a standard cash/dividends valuation model and find that oil price changes have a decisive effect on the real stock returns. Sadorsky (1999) using monthly data over the period 1947-1996 shows that an oil price shock has a negative and statistically significant initial impact on stock returns. Higher production costs due to higher oil prices will cause earnings to decline. An efficient stock market will react with an immediate decline in stock prices. Thus, individual oil price shocks depress real stock returns. Papapetrou (2001) examines the dynamic relationship among oil prices, real stock prices, interest rates, real economic activity and employment in Greece by using multivariate VAR approach and finds that oil price changes affect real economic activity and employment. Another finding of the paper is that oil prices are important in explaining stock price movements. Maghyereh (2004) investigates the linkages between crude oil price shocks and stock market returns in 22 emerging countries and finds that oil shocks have no significant impact on stock index returns. El-Sharif et al. (2005) examine the link between oil prices and measures of stock market performance. Hammoudeh and Choi (2006) examine the relationship between five Gulf Cooperation Council's stock markets and their links to the three Global factors - the WTI oil prices, the US 30 months treasury bill rate and S\&P 500 index. According to their findings, there is no direct effect of oil price on the S\&P 500 index. Anoruo and Mustafa (2007) investigate the relationship between oil prices and stock market returns for the United States by using cointegration techniques and modified VECM approach. Their results reveal evidence in favour of the cointegration between oil prices and stock markets and imply that the oil market accommodates changes in stock prices. Cong et al. (2008) investigate the interactive relationships between oil price shocks and Chinese stock market by using multivariate VAR model and find that oil price shocks do not show statistically significant impact on the real stock returns of most Chinese stock market indices. By analysing the US and 13 European countries, Park and Ratti (2008) conclude that the impacts of oil price 
shocks on the stock market of oil-importing countries are negative while the impacts on the stock market of oil-exporting countries are positive.

The aim of the paper is to investigate the long-run relationship between oil prices and stock market prices of G7 countries by using fractional integration and cointegration methods instead of the classical approach based on $I(0)$ stationarity or $I(1)$ cointegrating relationships. As a difference of the paper, we use different versions of Robinson (1994a) tests for fractional integration and cointegration following Gil-Alana (2003) and Caporale and Gil-Alana (2004). In their procedure, if the individual series are integrated of the same order according to the Robinson (1994a) test results, integration order of the residuals from the cointegrating regression is tested in the second step. As a result, there will be an evidence of fractional cointegration if the residuals have smaller integration order than the individual series. Robinson method has several distinguishing features compared with other procedures (Gil-Alana, 2004): It has standard (normal) null limit distribution and it is the most efficient one when directed against appropriate fractional alternatives. In addition, this standard distribution holds independently of the inclusion or noninclusion of deterministic components in the regression model.

The rest of the paper is structured as follows: Section 2 presents the Robinson (1994a) tests for fractional integration and cointegration. Section 3 describes data and reports the empirical results while Section 4 concludes.

\section{Robinson (1994a) Tests for Fractional Integration and Cointegration}

In this section, we describe the tests of Robinson (1994a), which is employed to analyze the fractional cointegration relationship between oil prices and stock market prices in G7 countries. In studies relying on standard cointegration analysis, the equilibrium errors are restricted to be an $I(0)$ process which is not persistent. However, it might be the case that the equilibrium errors respond more slowly to shocks which results in highly persistent deviations from equilibrium (Caporale and Gil-Alana, 2002). For this purpose, Robinson (1994a) considers the following regression model,

$$
y_{t}=\beta^{\prime} z_{t}+x_{t}, t=1,2, \ldots
$$

where $y_{t}$ is the observed time series for $t=1,2, \ldots T, \beta=\left(\beta_{1}, \ldots, \beta_{k}\right)^{\prime}$ is a $(k \times 1)$ vector of unknown parameters, $z_{t}$ is a $(k \times 1)$ vector of deterministic regressors such as an intercept or a linear trend. And the regression errors $x_{t}$ can be explained as follows:

$$
(1-L)^{d} x_{t}=u_{t}, t=1,2, \ldots
$$

where $L$ is the lag operator and $u_{t}$ is an $I(0)$ process. Here, $d$ can take any real value. If $d=0$ in equation (2), $x_{t}=u_{t}$ and a "weakly autocorrelated" $x_{t}$ is allowed for. When $d>0, x_{t}$ is said to be "strongly autocorrelated" or "strong dependent". Clearly, the unit root case corresponds to $\mathrm{d}=1$ in (2). If $d>0, X_{t}$ is said to be long memory (Granger and Joyeux, 1980; Hosking, 1981). If $0.5<d<1$, the process is nonstationary and exhibits long memory. If $0<d<0.5$, the process is stationary and exhibits long memory. It is important to note that when $d<0.5$ the process is stationary as well as mean reverting 
with the effect of the shocks dying away in the long run and when $0.5 \leq d$ the process is non-stationary even if the fractional parameter is significantly less than 1 .

Robinson (1994a) proposes Lagrange Multiplier (LM) test to test unit roots and other forms of nonstationary hypotheses, embedded in fractional alternatives. The null hypothesis of the test can be seen in below:

$$
H_{0}: d=d_{0}
$$

Specifically, the test statistic is given by:

where $\mathrm{T}$ is the sample size and

$$
\hat{r}=\frac{T^{1 / 2}}{\hat{\sigma}^{2}} \hat{A}^{1 / 2} \hat{a}
$$

$$
\begin{gathered}
\hat{a}=\frac{-2 \pi}{T} \sum_{j=1}^{T-1} \psi\left(\lambda_{j}\right) g\left(\lambda_{j} ; \hat{\tau}\right)^{-1} I\left(\lambda_{j}\right) ; \quad \hat{\sigma}^{2}=\sigma^{2}(\hat{\tau})=\frac{2 \pi}{T} \sum_{j=1}^{T-1} g\left(\lambda_{j} ; \hat{\tau}\right)^{-1} I\left(\lambda_{j}\right) ; \\
\hat{A}=\frac{2}{T}\left(\sum_{j=1}^{T-1} \psi\left(\lambda_{j}\right)^{2}-\sum_{j=1}^{T-1} \psi\left(\lambda_{j}\right) \hat{\varepsilon}\left(\lambda_{j}\right)^{\prime} \times\left(\sum_{j=1}^{T-1} \hat{\varepsilon}\left(\lambda_{j}\right) \hat{\varepsilon}\left(\lambda_{j}\right)^{\prime}\right)^{-1} \times \sum_{j=1}^{T-1} \hat{\varepsilon}\left(\lambda_{j}\right) \psi\left(\lambda_{j}\right)\right) \\
\psi\left(\lambda_{j}\right)=\log \left|2 \sin \frac{\lambda_{j}}{2}\right| ; \hat{\varepsilon}\left(\lambda_{j}\right)=\frac{\partial}{\partial \tau} \log g\left(\lambda_{j} ; \hat{\tau}_{j}\right) ; \lambda_{j}=\frac{2 \pi j}{T} ; \hat{\tau}=\arg \min _{\tau \in T^{*}} \sigma^{2}(\tau)
\end{gathered}
$$

where $I\left(\lambda_{j}\right)$ is the periodogram of $u_{t}$ and $T^{*}$ is a compact subset or the Euclidean space.

The main advantage of the Robinson (1994a) procedure is that it tests unit and fractional roots with a standard null limit distribution, which is unaffected by inclusion or not of deterministic trends. Under certain regularity conditions, Robinson (1994a) showed that the test statistic is

$$
\hat{r} \rightarrow_{d} N(0,1) \text { as } T \rightarrow \infty .
$$

Thus, a one sided $100 \alpha \%$ level test of $\mathrm{Eq}(3)$ against the alternative $H_{1}: d>d_{0}$ is given by the rule "Reject $H_{0}$ if $\hat{r}>z_{\alpha}$ " where the probability that a standard normal variate exceeds $z_{\alpha}$ is $\alpha$ and conversely, a one sided $100 \alpha \%$ level test of $\mathrm{Eq}(3)$ against the alternative $H_{1}: d>d_{0}$ is given by the rule "Reject $H_{0}$ if $\hat{r}<-z_{\alpha}$ ". Empirical applications of the test with this version and other versions can be found in Gil-Alana and Robinson (1997, 2001), Gil-Alana (1999, 2000, 2001, 2002b).

Gil-Alana (2003) and Caporale and Gil-Alana (2004) introduce the fractional cointegration concept and propose a procedure based on two steps. According to the simplest definition, a given vector $X_{t}$ is fractionally cointegrated if (Caporale and Gil-Alana, 2004):

i) all its components $\left(X_{i t}\right)$ are integrated of the same order $(d)$ and,

ii) there is at least one linear combination of these components which is fractionally integrated of order $b$, with $b<d$.

In the first step of their procedure, the integration orders of the individual series are tested by using Robinson (1994) tests and if all are integrated of the same order, in the second step, the integration order of the residuals from the cointegrating regression is 
tested. Gil-Alana (2003) and Caporale and Gil-Alana (2004) consider the following model for fractional cointegration:

$$
(1-L)^{d+\theta} e_{t}=v_{t}, \quad t=1,2, \ldots
$$

where $e_{t}$ are the OLS residuals from the cointegrating regression and $v_{t}$ is $I(0)$. The null $H_{0}: \theta=0$ hypothesis is tested against the one sided alternative $H_{1}: \theta<0$. If $H_{0}$ hypothesis on the estimated residuals is rejected, there will be an evidence of cointegration of a certain degree since the residuals will be integrated of a smaller order than the individual series. If we cannot reject the null hypothesis, no cointegration will be found since the integration order of the residuals will be same as the univariate series.

\section{Data and Empirical Results}

This study examines the fractional cointegration relationship between oil prices and stock market prices of G7 countries by using Robinson (1994a) tests. The empirical analysis has been carried out using monthly data for the period November 1990 to December 2009 for oil prices and stock prices of France (CAC 40), Germany (DAX 30), Japan (Nikkei 225), UK (FTSE 100) and USA (Dow Jones). The data cover the period from January 2000 through May 2009 for Italy (MIB 30) and cover the period from January 2000 through December 2009 for Canada (SP-TSX). As each market will be analyzed separately, different sample periods should not pose any problem to our study. The data on oil prices (in USD per barrel) come from Energy Information Administration (EIA) and stock market prices data are from DataStream. In the analysis, we take the natural logarithm of each variable. Table 1 provides several descriptive statistics, including mean $(\bar{X})$, standard deviation ( $\hat{\sigma})$, skewness $\left(\tau_{3}\right)$, excess kurtosis $\left(\tau_{4}\right)$, Jarque-Bera $(\mathrm{JB})$ statistic and the first order autocorrelation coefficient $\left(\rho_{1}\right)$.

Table 1

Descriptive Statistics for the Series

\begin{tabular}{|l|c|c|c|c|c|c|c|}
\hline Series & $\boldsymbol{T}$ & $\bar{X}$ & $\hat{\sigma}$ & $\tau_{3}$ & $\tau_{4}$ & JB & $\hat{\rho}_{1}$ \\
\hline Oil Prices & 230 & 1.452 & 0.258 & 0.690 & 2.473 & $20.942^{\mathrm{a}}$ & $0.983^{\mathrm{a}}$ \\
\hline CAC 40 & 230 & 3.512 & 0.181 & -0.114 & 1.684 & $17.092^{\mathrm{a}}$ & $0.984^{\mathrm{a}}$ \\
\hline DAX 30 & 230 & 3.567 & 0.221 & -0.361 & 1.816 & $18.434^{\mathrm{a}}$ & $0.983^{\mathrm{a}}$ \\
\hline DOW JONES & 230 & 3.376 & 0.192 & -0.546 & 2.027 & $20.492^{\mathrm{a}}$ & $0.983^{\mathrm{a}}$ \\
\hline FTSE 100 & 230 & 3.641 & 0.134 & -0.513 & 2.124 & $17.459^{\mathrm{a}}$ & $0.978 \mathrm{a}$ \\
\hline MIB 30 & 113 & 4.377 & 0.104 & -0.481 & 2.448 & $5.798^{\mathrm{b}}$ & $0.954^{\mathrm{a}}$ \\
\hline NIKKEI 225 & 230 & 4.178 & 0.128 & -0.411 & 2.244 & $11.967^{\mathrm{a}}$ & $0.971^{\mathrm{a}}$ \\
\hline SP-TSX & 120 & 3.982 & 0.104 & 0.058 & 1.914 & $5.958^{\mathrm{b}}$ & $0.976^{\mathrm{a}}$ \\
\hline
\end{tabular}

${ }^{a}$ and ${ }^{b}$ denote statistical significance at $1 \%$ and $5 \%$ levels, respectively.

The values in the table give some information about the distribution of the series. Both skewness and kurtosis statistics indicate that distributions are not normal. Employing JB statistics, it is concluded that there are significant departures from 
normality. The significance of $\rho_{1}$ in all series suggests the presence of short term dependence. As a first step of the analysis, we examine seasonality for monthly data by using eleven dummy variables, each representing one of the months in a year. Since the dummy variables are insignificant, they are not taken into account in the analysis. The next step of the analysis is to investigate the unit root properties of the oil prices and stock market prices by using Augmented Dickey Fuller (ADF), Philips and Perron (PP) and Kwiatkowski, Philips, Schmidt and Shin (KPSS) unit root tests. The results are presented in Table $2 .^{1}$

Table 2

The Results of ADF, PP and KPSS Unit Root Tests

\begin{tabular}{|l|c|c|c|c|c|c|}
\hline & \multicolumn{2}{|c|}{ ADF } & \multicolumn{2}{c|}{ PP } & \multicolumn{2}{c|}{ KPSS } \\
\hline Variables & Intercept & $\begin{array}{c}\text { Intercept } \\
\text { and Trend }\end{array}$ & Intercept & $\begin{array}{c}\text { Intercept } \\
\text { and Trend }\end{array}$ & Intercept & $\begin{array}{c}\text { Intercept } \\
\text { and Trend }\end{array}$ \\
\hline Oil Prices & $-0.94(1)$ & $-3.19(1)^{\mathrm{b}}$ & $-0.92(4)$ & $-3.43(5)^{\mathrm{b}}$ & $1.57(11)^{\mathrm{a}}$ & $0.34(11)^{\mathrm{a}}$ \\
\hline$\Delta$ Oil Prices & $-12.20(0)^{\mathrm{a}}$ & - & $-12.20(0)^{\mathrm{a}}$ & & $0.18(4)$ & $0.04(4)$ \\
\hline CAC 40 & $-1.85(1)$ & $-1.56(1)$ & $-1.72(5)$ & $-1.54(5)$ & $1.29(11)^{\mathrm{a}}$ & $0.23(11)^{\mathrm{a}}$ \\
\hline ACAC 40 & $-13.72(0)^{\mathrm{a}}$ & $-13.77(0)^{\mathrm{a}}$ & $-13.76(4)^{\mathrm{a}}$ & $-13.80(4)^{\mathrm{a}}$ & $0.16(5)$ & $0.06(5)$ \\
\hline DAX 30 & $-1.61(0)$ & $-1.58(0)$ & $-1.65(5)$ & $-1.77(5)$ & $1.39(11)^{\mathrm{a}}$ & $0.25(11)^{\mathrm{a}}$ \\
\hline ADAX 30 & $-14.30(0)^{\mathrm{a}}$ & $-14.31(0)^{\mathrm{a}}$ & $-14.35(4)^{\mathrm{a}}$ & $-14.36(4)^{\mathrm{a}}$ & $0.12(5)$ & $0.06(5)$ \\
\hline DOW JONES & $-2.16(0)$ & $-1.72(1)$ & $-2.09(6)$ & $-1.85(6)$ & $1.70(11)^{\mathrm{a}}$ & $0.30(11)^{\mathrm{a}}$ \\
\hline DDOW JONES & $-13.81(0)^{\mathrm{a}}$ & $-13.91(0)^{\mathrm{a}}$ & $-13.89(6)^{\mathrm{a}}$ & $-13.97(5)^{\mathrm{a}}$ & $0.24(6)$ & $0.04(6)$ \\
\hline FSTE 100 & $-1.87(4)$ & $-1.79(4)$ & $-2.21(6)$ & $-1.85(6)$ & $1.18(11)^{\mathrm{a}}$ & $0.31(11)^{\mathrm{a}}$ \\
\hline$\Delta$ FSTE 100 & $-6.40(3)^{\mathrm{a}}$ & $-6.44(3)^{\mathrm{a}}$ & $-13.98(6)^{\mathrm{a}}$ & $-14.04(5)^{\mathrm{a}}$ & $0.23(6)$ & $0.06(6)$ \\
\hline MIB 30 & $-1.62(3)$ & $-1.62(3)$ & $-1.10(5)$ & $-1.18(5)$ & $1.14(9)^{\mathrm{a}}$ & $0.14(9)^{\mathrm{b}}$ \\
\hline$\Delta$ MIB 30 & $-10.09(0)^{\mathrm{a}}$ & $-10.02(0)^{\mathrm{a}}$ & $-10.13(0)^{\mathrm{a}}$ & $-10.07(0)^{\mathrm{a}}$ & $0.14(5)$ & $0.02(5)$ \\
\hline NIKKEI 225 & $-1.87(1)$ & $-2.43(1)$ & $-1.82(5)$ & $-2.54(6)$ & $1.18(11)^{\mathrm{a}}$ & $0.12(11)^{\mathrm{c}}$ \\
\hline$\Delta$ NIKKEI 225 & $-13.95(0)^{\mathrm{a}}$ & $-13.91(0)^{\mathrm{a}}$ & $-13.97(4)^{\mathrm{a}}$ & $-13.94(4)^{\mathrm{a}}$ & $0.04(5)$ & $0.04(5)$ \\
\hline SP-TSX & $-1.29(1)$ & $-2.52(5)$ & $-1.37(6)$ & $-1.94(6)$ & $0.75(9)^{\mathrm{a}}$ & $0.14(9)^{\mathrm{b}}$ \\
\hline$\Delta$ SP-TSX & $-8.32(0)^{\mathrm{a}}$ & $-8.29(0)^{\mathrm{a}}$ & $-8.38(5)^{\mathrm{a}}$ & $-8.35(5)^{\mathrm{a}}$ & $0.08(5)$ & $0.08(5)$ \\
\hline
\end{tabular}

a,b,c indicate significance at $1 \%, 5 \%$ and $10 \%$ levels, respectively. The critical values of ADF and PP unit root tests are $-3.458,-2.873$ and -2.573 at $1 \%, 5 \%$ and $10 \%$ levels of significance for models without trend; $3.998,-3.429$ and -3.138 at $1 \%, 5 \%$ and $10 \%$ levels of significance for models with trend, respectively. The critical values for KPSS test are $0.739,0.463$ and 0.347 at $1 \%, 5 \%$ and $10 \%$ levels of significance for models without trend; $0.216,0.146$ and 0.119 at $1 \%, 5 \%$ and $10 \%$ levels of significance for models with trend, respectively.

1 We also apply unit root tests for oil prices over the period from January 2000 through May 2009 and over the period from January 2000 through December 2009 but we do not report them in the table. The results show that oil prices are stationary after first differencing. They are available on request. 
Table 3

Robinson (1994a) Test Results for Fractional Integration

\begin{tabular}{|c|c|c|c|c|c|c|c|c|}
\hline \multirow[b]{2}{*}{$d_{o}$} & \multicolumn{2}{|c|}{ Oil Prices } & \multicolumn{2}{|c|}{ CAC 40} & \multicolumn{2}{|c|}{ DAX 30} & \multicolumn{2}{|c|}{ DOW JONES } \\
\hline & White Noise & $\operatorname{AR}(1)$ & White Noise & $A R(1)$ & White Noise & $A R(1)$ & White Noise & $A R(1)$ \\
\hline 0 & 26.15 & 336.98 & 32.39 & 525.19 & 33.52 & 593.89 & 32.59 & 568.40 \\
\hline 0.05 & 24.76 & 298.31 & 31.88 & 487.07 & 32.87 & 538.22 & 31.95 & 525.61 \\
\hline 0.10 & 23.31 & 258.99 & 31.28 & 442.32 & 32.10 & 475.19 & 31.18 & 473.66 \\
\hline 0.15 & 21.81 & 220.08 & 30.57 & 391.80 & 31.18 & 408.05 & 30.25 & 414.27 \\
\hline 0.20 & 20.26 & 182.99 & 29.71 & 337.65 & 30.11 & 340.83 & 29.15 & 350.96 \\
\hline 0.25 & 18.69 & 149.22 & 28.69 & 282.99 & 28.86 & 277.43 & 27.84 & 288.10 \\
\hline 0.30 & 17.11 & 119.86 & 27.48 & 231.11 & 27.42 & 220.84 & 26.31 & 229.82 \\
\hline 0.35 & 15.53 & 95.24 & 26.06 & 184.60 & 25.77 & 172.74 & 24.56 & 178.99 \\
\hline 0.40 & 13.97 & 75.13 & 24.42 & 144.90 & 23.93 & 133.46 & 22.60 & 136.87 \\
\hline 0.45 & 12.44 & 58.97 & 22.56 & 112.35 & 21.90 & 102.37 & 20.46 & 103.37 \\
\hline 0.50 & 10.95 & 46.15 & 20.52 & 86.48 & 19.74 & 78.29 & 18.20 & 77.54 \\
\hline 0.55 & 9.52 & 36.06 & 18.33 & 66.37 & 17.47 & 59.91 & 15.86 & 58.04 \\
\hline 0.60 & 8.15 & 28.16 & 16.05 & 50.94 & 15.17 & 45.95 & 13.53 & 43.48 \\
\hline 0.65 & 6.86 & 21.99 & 13.74 & 39.15 & 12.88 & 35.35 & 11.26 & 32.64 \\
\hline 0.70 & 5.64 & 17.15 & 11.47 & 30.11 & 10.67 & 27.22 & 9.12 & 24.51 \\
\hline 0.75 & 4.50 & 13.29 & 9.31 & 23.08 & 8.59 & 20.87 & 7.14 & 18.31 \\
\hline 0.80 & 3.44 & 10.16 & 7.31 & 17.51 & 6.67 & 15.77 & 5.36 & 13.45 \\
\hline 0.85 & 2.46 & 7.52 & 5.49 & 12.98 & 4.93 & 11.55 & 3.77 & 9.52 \\
\hline 0.90 & $1.57^{\mathrm{b}}$ & 5.22 & 3.87 & 9.20 & 3.39 & 7.97 & 2.39 & 6.23 \\
\hline 0.95 & $0.75^{b}$ & 3.14 & 2.45 & 5.99 & 2.04 & 4.86 & $1.20^{\mathrm{b}}$ & 3.42 \\
\hline 1 & $0.00^{\mathrm{b}}$ & $1.21^{\mathrm{b}}$ & $1.23^{b}$ & 3.23 & $0.86^{\mathrm{b}}$ & 2.14 & $0.17^{\mathrm{b}}$ & $0.97^{b}$ \\
\hline 1.05 & $-0.67^{b}$ & $-0.59^{b}$ & $0.18^{b}$ & $0.86^{b}$ & $-0.16^{b}$ & $-0.24^{b}$ & $-0.71^{b}$ & $-1.14^{b}$ \\
\hline \multirow[t]{2}{*}{1.10} & $-1.29^{b}$ & -2.27 & $-0.72^{b}$ & $-1.19^{b}$ & $-1.03^{b}$ & -2.31 & $-1.46^{b}$ & -2.97 \\
\hline & \multicolumn{2}{|c|}{ FSTE 100} & \multicolumn{2}{|c|}{ MIB 30} & \multicolumn{2}{|c|}{ NIKKEI 225} & \multicolumn{2}{|c|}{ SP-TSX } \\
\hline$d_{o}$ & White Noise & $A R(1)$ & White Noise & $A R(1)$ & White Noise & $A R(1)$ & White Noise & $A R(1)$ \\
\hline 0 & 34.13 & 638.30 & 17.19 & 159.09 & 30.16 & 387.12 & 19.22 & 179.34 \\
\hline 0.05 & 33.47 & 596.12 & 16.89 & 151.15 & 29.23 & 332.19 & 18.72 & 171.47 \\
\hline 0.10 & 32.66 & 542.89 & 16.57 & 141.78 & 28.20 & 280.61 & 18.15 & 162.14 \\
\hline 0.15 & 31.67 & 479.41 & 16.21 & 131.01 & 27.05 & 233.72 & 17.51 & 150.77 \\
\hline 0.20 & 30.46 & 408.82 & 15.81 & 119.09 & 25.80 & 192.26 & 16.78 & 137.09 \\
\hline 0.25 & 29.03 & 336.10 & 15.35 & 106.44 & 24.42 & 156.53 & 15.97 & 121.33 \\
\hline 0.30 & 27.34 & 266.81 & 14.83 & 93.51 & 22.92 & 126.43 & 15.09 & 104.33 \\
\hline 0.35 & 25.41 & 205.46 & 14.22 & 80.79 & 21.31 & 101.53 & 14.13 & 87.34 \\
\hline 0.40 & 23.26 & 154.52 & 13.52 & 68.68 & 19.60 & 81.26 & 13.10 & 71.56 \\
\hline 0.45 & 20.92 & 114.36 & 12.73 & 57.54 & 17.81 & 64.95 & 12.04 & 57.79 \\
\hline 0.50 & 18.46 & 83.90 & 11.83 & 47.59 & 15.97 & 51.93 & 10.94 & 46.33 \\
\hline 0.55 & 15.94 & 61.39 & 10.84 & 38.96 & 14.11 & 41.57 & 9.84 & 37.07 \\
\hline 0.60 & 13.44 & 44.98 & 9.76 & 31.64 & 12.26 & 33.32 & 8.74 & 29.71 \\
\hline 0.65 & 11.05 & 33.06 & 8.63 & 25.56 & 10.46 & 26.70 & 7.67 & 23.89 \\
\hline 0.70 & 8.81 & 24.33 & 7.46 & 20.55 & 8.73 & 21.33 & 6.63 & 19.28 \\
\hline 0.75 & 6.78 & 17.82 & 6.30 & 16.44 & 7.11 & 16.88 & 5.64 & 15.59 \\
\hline 0.80 & 4.96 & 12.84 & 5.16 & 13.03 & 5.60 & 13.13 & 4.71 & 12.60 \\
\hline 0.85 & 3.38 & 8.88 & 4.08 & 10.15 & 4.22 & 9.89 & 3.84 & 10.11 \\
\hline 0.90 & 2.02 & 5.64 & 3.08 & 7.67 & 2.97 & 7.04 & 3.02 & 8.00 \\
\hline 0.95 & $0.85^{b}$ & 2.89 & 2.17 & 5.47 & 1.85 & 4.50 & 2.27 & 6.14 \\
\hline 1 & $-0.14^{b}$ & $0.54^{b}$ & $1.35^{b}$ & 3.51 & $0.86^{\mathrm{b}}$ & 2.23 & $1.57^{\mathrm{b}}$ & 4.48 \\
\hline 1.05 & $-0.97^{b}$ & $-1.48^{b}$ & $0.63^{b}$ & 1.75 & $-0.02^{b}$ & $0.20^{b}$ & $0.94^{b}$ & 2.96 \\
\hline 1.10 & -1.68 & -3.22 & $-0.01^{b}$ & $0.18^{\mathrm{b}}$ & $-0.79^{b}$ & $-1.61^{b}$ & $0.36^{\mathrm{b}}$ & $1.55^{\mathrm{b}}$ \\
\hline
\end{tabular}

${ }^{b}$ and in bold: Non rejection values of the null hypothesis at the $95 \%$ significance level. 
The ADF and PP unit root tests results show that oil prices are stationary after first differencing in the cases with intercept but it is found stationary in the level with intercept and trend. The results for stock market prices indicate that all of them are stationary after first differencing. It is known that standard ADF and PP tests are not very informative on how to distinguish between a unit root and near unit root cases and they have low power in small sample size. Therefore the alternative KPSS test is used to confirm the results of both ADF and PP tests. The KPSS test, which is suggested by Kwiatkowski et al. (1992), has the advantage of allowing for weakly dependent and nonhomogeneously distributed errors. This test differs from other unit root tests in that the series are assumed to be stationary under the null. According to the KPSS test results, the null hypothesis is rejected in favour of the unit root hypothesis for all cases at levels. These findings confirm that all series are stationary after first differencing. However, these unit root tests do not take account of the possible long memory properties of the series. Therefore, we also apply different versions of Robinson (1994a) tests to examine the long memory properties of the data. Under the null hypothesis $H_{0}(3)$, we examine the cases with an intercept and a linear time trend and model the $I(0)$ disturbances to be both white noise and AR(1) processes. Table 3 reports the one sided test statistics $\hat{r}$ with $d_{0}=0,0.05,0.10,0.15,0.20,0.25, \ldots ., 1.10$, thus testing for a unit root $(d=1)$, but also including a test for stationarity $(\mathrm{d}=0.5)$ and for other fractional alternatives. ${ }^{2}$ For a given $d_{0}$, significantly positive values of $\hat{r}$ are consistent with the orders of integration higher than $d_{0}$, whereas significantly negative ones consistent with the orders of integration smaller than $d_{0}$. A notable feature is the fact that $\hat{r}$ monotonically decreases with $d_{0}$. This is something to be expected since it is a one sided test statistic.

The results for oil prices show that if the disturbances are white noise, $H_{0}(3)$ cannot be rejected for the values of $d_{0}=0.90,0.95,1,1.05$ and 1.10. If we assume an AR(1) process for the $u_{t}$ disturbances in (2), the non rejection values occur when $d_{0}=1$ and 1.05 for oil prices. According to the results for stock market prices in the case of white noise disturbances, the non-rejection values take place at $d_{0}=1,1.05$ and 1.10 for the indices of CAC 40, DAX 30, MIB 30, Nikkei 225, SP-TSX and the non-rejection values occur when $d_{0}=0.95,1,1.05,1.10$ for Dow Jones index, $d_{0}=0.95,1,1.05$ for FTSE 100 index. In the case of AR(1) disturbances, $d_{0}=1,1.05$ values for Dow Jones and FTSE 100 indices, $d_{0}=1.05,1.10$ values for CAC 40 and Nikkei 225 indices, $d_{0}=1.10$ value for MIB 30 and SP-TSX indices and $d_{0}=1.05$ value for DAX 30 index cannot be rejected. It is seen that unit root null hypothesis $(\mathrm{d}=1)$ cannot be rejected for all univariate series. These results indicate that all series may be integrated of order 1 , although other fractional orders of integration lower than or higher than 1, also appear to be plausible in some cases. Having found that individual series have unit root, it is examined whether oil prices and stock market prices have a fractional cointegration relationship. The OLS estimation results of the cointegrating regressions are reported in Table 4.

2 Robinson(1994a) tests are also performed for oil prices over the period from January 2000 through May 2009 and over the period from January 2000 through December 2009. The results give the same integration orders. They are available on request. 
Table 4

Estimation Results from the Cointegrating Regressions

Model: Stock Market Prices $=\alpha+\beta$ (Oil Prices)

\begin{tabular}{|c|c|c|}
\hline Stock Market Prices & $\alpha$ & $\beta$ \\
\hline CAC 40 & $\begin{array}{c}2.957^{\mathrm{a}} \\
(51.292)\end{array}$ & $\begin{array}{c}0.381^{a} \\
(9.769)\end{array}$ \\
\hline DAX 30 & $\begin{array}{c}2.861^{\mathrm{a}} \\
(41.448) \\
\end{array}$ & $\begin{array}{c}0.485^{a} \\
(10.372) \\
\end{array}$ \\
\hline DOW JONES & $\begin{array}{c}2.658^{a} \\
(48.982)\end{array}$ & $\begin{array}{c}0.494^{a} \\
(13.435)\end{array}$ \\
\hline FTSE 100 & $\begin{array}{c}3.310^{\mathrm{a}} \\
(72.414)\end{array}$ & $\begin{array}{l}0.228^{a} \\
(7.367)\end{array}$ \\
\hline MIB 30 & $\begin{array}{c}4.192^{\mathrm{a}} \\
(56.961)\end{array}$ & $\begin{array}{c}0.113^{\mathrm{a}} \\
(2.523)\end{array}$ \\
\hline NIKKEI 225 & $\begin{array}{c}4.460^{\mathrm{a}} \\
(99.695)\end{array}$ & $\begin{array}{r}-0.194^{a} \\
(-6.409)\end{array}$ \\
\hline SP-TSX & $\begin{array}{c}3.293^{a} \\
(89.208)\end{array}$ & $\begin{array}{c}0.419^{a} \\
(18.812)\end{array}$ \\
\hline
\end{tabular}

The numbers in parenhesis are t-values. ${ }^{a}$ indicates statistically significance at $1 \%$ level.

The results indicate that all the coefficients are statistically significant and all of them are positive except $\beta$ coefficient for Nikkei 225 index. It means that oil prices have a negative effect on Nikkei 225 index and have a positive effect on the remaining indices. In the next step of the analysis, we investigate whether the estimated residuals from these cointegrating regressions have an integration order smaller than the individual series $(\mathrm{d}<1)$. It is known that there will be an evidence of fractional cointegration if the residuals have smaller integration order than the individual series. In order to investigate it, Robinson (1994a) tests are applied for the estimated residuals following Gil-Alana (2003) and Caporale and Gil-Alana (2004). Table 5 reports values of the one sided statistic $\hat{r}$ under the assumptions of white noise and AR(1) disturbances.

Here, we can still rely on the asymtotic critical values. The fact that the least square estimations of the cointegrating parameters are consistent estimates of the true value under cointegration, allows to use the asymptotic critical values given by the normal distribution when testing $\mathrm{d}$ for the estimated residuals (Caporale and Gil-Alana, 2004). The results in the table show that if the disturbances are white noise, the non-rejection values take place at $d_{0}=0.80,0.85,0.90$ and 0.95 for Dow Jones index. Because of that the residuals for Dow Jones index have smaller integration order than the individual oil prices and Dow Jones index series, it can be said that there is evidence of fractional cointegration between oil prices and Dow Jones index. On the other hand, if the disturbances are AR(1), the unit root null hypothesis is rejected in the cases of Dax 30, Dow Jones, FTSE 100 and SP-TSX. In details, $d_{0}=0.95$ value for DAX 30 and FTSE $100, d_{0}=0.90$ value for Dow Jones and $d_{0}=0.85$ and 0.90 values for SP-TSX cannot be rejected. 
Table 5

\section{Testing the Order of Integration of the Residuals from the Cointegrating Regressions}

\begin{tabular}{|c|c|c|c|c|c|c|c|c|}
\hline \multirow[b]{2}{*}{$d_{0}$} & \multicolumn{2}{|c|}{ CAC 40} & \multicolumn{2}{|c|}{ DAX 30} & \multicolumn{2}{|c|}{ DOW JONES } & \multicolumn{2}{|c|}{ FSTE 100} \\
\hline & White Noise & $A R(1)$ & White Noise & $A R(1)$ & White Noise & $A R(1)$ & White Noise & $A R(1)$ \\
\hline 0 & 33.32 & 580.38 & 33.58 & 621.72 & 32.88 & 595.74 & 34.30 & 662.17 \\
\hline 0.05 & 32.55 & 539.83 & 32.63 & 570.91 & 31.73 & 559.03 & 33.44 & 629.00 \\
\hline 0.10 & 31.60 & 488.66 & 31.49 & 507.86 & 30.33 & 511.55 & 32.37 & 584.54 \\
\hline 0.15 & 30.45 & 427.20 & 30.12 & 434.78 & 28.66 & 451.45 & 31.04 & 526.73 \\
\hline 0.20 & 29.07 & 358.68 & 28.52 & 356.81 & 26.71 & 379.67 & 29.45 & 455.80 \\
\hline 0.25 & 27.44 & 288.90 & 26.68 & 280.97 & 24.52 & 301.79 & 27.57 & 375.82 \\
\hline 0.30 & 25.56 & 224.21 & 24.61 & 213.54 & 22.12 & 226.74 & 25.42 & 294.22 \\
\hline 0.35 & 23.43 & 168.96 & 22.35 & 158.11 & 19.57 & 162.73 & 23.04 & 219.49 \\
\hline 0.40 & 21.11 & 124.76 & 19.96 & 115.18 & 16.96 & 113.35 & 20.47 & 157.57 \\
\hline 0.45 & 18.66 & 91.05 & 17.48 & 83.28 & 14.38 & 77.80 & 17.80 & 110.29 \\
\hline 0.50 & 16.14 & 66.15 & 15.00 & 60.17 & 11.89 & 53.22 & 15.13 & 76.20 \\
\hline 0.55 & 13.63 & 48.09 & 12.59 & 43.63 & 9.57 & 36.54 & 12.53 & 52.51 \\
\hline 0.60 & 11.23 & 35.08 & 10.30 & 31.81 & 7.46 & 25.26 & 10.08 & 36.32 \\
\hline 0.65 & 8.98 & 25.67 & 8.20 & 23.29 & 5.58 & 17.52 & 7.85 & 25.27 \\
\hline 0.70 & 6.93 & 18.75 & 6.29 & 17.01 & 3.94 & 12.05 & 5.86 & 17.61 \\
\hline 0.75 & 5.11 & 13.53 & 4.60 & 12.24 & 2.52 & 8.00 & 4.12 & 12.13 \\
\hline 0.80 & 3.52 & 9.46 & 3.12 & 8.46 & $1.31^{\mathrm{b}}$ & 4.82 & 2.63 & 8.04 \\
\hline 0.85 & 2.15 & 6.16 & 1.83 & 5.34 & $0.28^{\mathrm{b}}$ & 2.18 & $1.36^{\mathrm{b}}$ & 4.81 \\
\hline 0.90 & $0.98^{b}$ & 3.41 & $0.73^{b}$ & 2.68 & $-0.59^{b}$ & $-0.09^{b}$ & $0.29^{b}$ & 2.14 \\
\hline 0.95 & $-0.01^{b}$ & $1.08^{b}$ & $-0.22^{b}$ & $0.37^{b}$ & $-1.33^{b}$ & -2.06 & $-0.61^{b}$ & $-0.14^{b}$ \\
\hline 1 & $-0.85^{b}$ & $-0.93^{b}$ & $-1.02^{b}$ & -1.65 & -1.96 & -3.75 & $-1.36^{b}$ & -2.12 \\
\hline 1.05 & $-1.56^{b}$ & -2.66 & -1.71 & -3.40 & -2.49 & -5.18 & -2.00 & -3.81 \\
\hline \multirow[t]{2}{*}{1.10} & -2.16 & -4.14 & -2.31 & -4.91 & -2.95 & -6.39 & -2.53 & -5.26 \\
\hline & \multicolumn{2}{|r|}{ MIB 30} & \multicolumn{2}{|c|}{ NIKKEI 225} & \multicolumn{2}{|r|}{ SP-TSX } & & \\
\hline$d_{0}$ & White Noise & $A R(1)$ & White Noise & $A R(1)$ & White Noise & $A R(1)$ & & \\
\hline 0 & 17.40 & 159.97 & 29.66 & 402.35 & 16.04 & 100.47 & & \\
\hline 0.05 & 17.08 & 150.26 & 28.75 & 351.63 & 15.29 & 86.08 & & \\
\hline 0.10 & 16.72 & 138.89 & 27.75 & 302.37 & 14.46 & 72.84 & & \\
\hline 0.15 & 16.32 & 126.13 & 26.67 & 256.12 & 13.57 & 61.02 & & \\
\hline 0.20 & 15.85 & 112.45 & 25.49 & 214.03 & 12.60 & 50.73 & & \\
\hline 0.25 & 15.32 & 98.43 & 24.22 & 176.77 & 11.58 & 41.95 & & \\
\hline 0.30 & 14.70 & 84.63 & 22.85 & 144.56 & 10.51 & 34.57 & & \\
\hline 0.35 & 13.98 & 71.55 & 21.40 & 117.30 & 9.42 & 28.42 & & \\
\hline 0.40 & 13.15 & 59.58 & 19.85 & 94.65 & 8.30 & 23.33 & & \\
\hline 0.45 & 12.22 & 48.98 & 18.24 & 76.09 & 7.20 & 19.12 & & \\
\hline 0.50 & 11.18 & 39.85 & 16.57 & 61.07 & 6.11 & 15.59 & & \\
\hline 0.55 & 10.05 & 32.18 & 14.87 & 49.02 & 5.06 & 12.60 & & \\
\hline 0.60 & 8.85 & 25.85 & 13.17 & 39.40 & 4.07 & 10.02 & & \\
\hline 0.65 & 7.61 & 20.65 & 11.49 & 31.71 & 3.14 & 7.74 & & \\
\hline 0.70 & 6.37 & 16.39 & 9.85 & 25.52 & 2.27 & 5.69 & & \\
\hline 0.75 & 5.15 & 12.85 & 8.28 & 20.50 & $1.48^{\mathrm{b}}$ & 3.83 & & \\
\hline 0.80 & 4.00 & 9.85 & 6.80 & 16.34 & $0.76^{\mathrm{b}}$ & 2.13 & & \\
\hline 0.85 & 2.94 & 7.23 & 5.41 & 12.83 & $0.12^{b}$ & $0.58^{\mathrm{b}}$ & & \\
\hline 0.90 & 1.97 & 4.91 & 4.14 & 9.78 & $-0.46^{b}$ & $-0.82^{b}$ & & \\
\hline 0.95 & $1.11^{\mathrm{b}}$ & 2.84 & 2.98 & 7.08 & $-0.98^{b}$ & -2.08 & & \\
\hline 1 & $0.35^{b}$ & $1.00^{b}$ & 1.92 & 4.66 & $-1.44^{b}$ & -3.20 & & \\
\hline 1.05 & $-0.31^{b}$ & $-0.62^{b}$ & $0.98^{b}$ & 2.46 & -1.85 & -4.18 & & \\
\hline 1.10 & $-0.89^{b}$ & -2.02 & $0.13^{b}$ & $0.47^{b}$ & -2.21 & -5.05 & & \\
\hline
\end{tabular}

b and in bold: Non rejection values of the null hypothesis at the $95 \%$ significance level. 
These results indicate that integration orders of the residuals for Dax 30, Dow Jones, FTSE 100 and SP-TSX indices are smaller than the individual series. In other words, fractional cointegration is found between oil prices and Dax 30, Dow Jones, FTSE 100 and SP-TSX indices if the disturbances are AR(1). Because of that unit root null hypothesis cannot be rejected for CAC 40, MIB 30 and the integration order of the residuals for Nikkei 225 is bigger than 1, there is no evidence of fractional cointegration between oil prices and corresponding indices.

To sum up, this paper gives mixed results based on the disturbances. If the disturbances are assumed to be white noise, there is evidence of fractional cointegration between oil prices and Dow Jones index. If the disturbances are AR(1), fractional cointegration is found between oil prices and Dax 30, Dow Jones, FTSE 100 and SP-TSX indices.

\section{Conclusions}

In this paper, long-run relationship between oil prices and stock market prices of G7 countries is investigated by using Robinson (1994a) tests for fractional integration and cointegration. For monthly data, at first, we examine seasonality by using eleven dummy variables, each representing one of the months in a year. Since the dummy variables are insignificant, they are not taken into account in the analysis. To investigate the unit root properties of the series, we use ADF, PP and KPSS unit root tests and find that all series are stationary after first differencing. It is known that these unit root tests do not take account of the possible long memory properties. Therefore, we also apply different versions of Robinson (1994a) tests to examine the long memory properties of the data. The test results for individual series indicate that unit root null hypothesis $(d=1)$ cannot be rejected for all the series. Having found that the series may be integrated of order 1, although other fractional orders of integration lower than or higher than 1, also appear to be plausible in some cases, we examine whether oil prices and stock market prices have a fractional cointegration relationship. Following Gil-Alana (2003) and Caporale and Gil-Alana (2004), Robinson (1994a) tests are applied on the residuals from the cointegrating regressions. The finding results show that there is evidence of fractional cointegration between oil prices and Dow Jones index if the disturbances are white noise. For $\mathrm{AR}(1)$ disturbances, fractional cointegration is found between oil prices and Dax 30, Dow Jones, FTSE 100 and SP-TSX indices. But, there is no evidence of fractional cointegration for CAC 40, MIB 30 and Nikkei 225 indices. 


\section{References}

Anoruo, E., Mustafa, M. (2007), "An Empirical Investigation into the Relation of Oil to Stock Market Prices." North American Journal of Finance and Banking Research, Vol.1, pp. 22-36.

Basher, S. A., Sadorsky, P. (2006), "Oil Price Risk and Emerging Stock Markets." Global Finance Journal, Vol.17, pp. 224-251.

Brown, S. P., Yücel, M. K. (2002), "Energy Prices and Aggregate Economic Activity: An Interpretative Survey." Quarterly Review of Economics and Finance, Vol. 42, pp. 193-208.

Caporale, G. M., Gil-Alana, L. A. (2004), "Fractional Cointegration and Tests of Present Value Models." Review of Financial Economics, Vol.13, pp. 245-258.

Caporale, G. M., Gil-Alana, L. A. (2002), "Unemployment and Input Prices: A Fractional Cointegration Approach." Applied Economics Letters, Vol. 9, pp. 347-351.

Cong, R. G. et al. (2008), "Relationships Between Oil Price Shocks and Stock Market: An Empirical Analysis From China." Energy Policy, Vol. 36, pp. 3544-3553.

El-Sharif, I. et al. (2005), "Evidence on the Nature and Extent of the Relationship between Oil Prices and Equity Values in the UK." Energy Economics, Vol. 27, pp. 819-830.

Gil-Alana, L. A. (1999), "Testing of Fractional Integration with Monthly Data." Economic Modelling, Vol. 16, pp. 613-629.

Gil-Alana, L. A. (2000), "Mean Reversion in the Real Exchange Rates." Economics Letters, Vol. 16, pp. 285-288.

Gil-Alana, L. A. (2001). "Testing of Stochastic Cycles in Macroeconomic Time Series." Journal of Time Series Analysis, Vol. 22, pp. 411-430.

Gil-Alana, L. A. (2002b), "Structural Breaks and Fractional Integration in the US Output and Unemployment Rate." Economics Letters, Vol. 77, pp. 79-84.

Gil-Alana, L. A. (2003), "Fractional Cointegration in Macroeconomic Time Series." Oxford Bulletin of Economics and Statistics, Vol. 65, pp. 517-524.

Gil-Alana, L. A. (2004), "Long Memory in the U.S. Interest Rate." International Review of Financial Analysis, Vol. 13, pp. 265-276.

Gil-Alana, L. A., Robinson, P. M. (1997), "Testing of Unit Roots and Other Nonstationary Hypothesis in Macroeconomic Time Series." Journal of Econometrics, Vol.80, pp. 241-268.

Gil-Alana, L. A., Robinson, P. M. (2001), "Testing of Seasonal Fractional Integration in the UK and Japanese Consumption and Income." Journal of Applied Econometrics, Vol.16, pp. 95-114.

Granger, C. W. J., Joyeux, R. (1980), "An Introduction to Long-Memory Time Series Models and Fractional Differencing." Journal of Time Series Analysis, Vol.1, pp. 15-29.

Hammoudeh, S., Choi, K. (2006), "Behavior of GCC Stock Markets and Impacts of US Oil and Financial Markets." Research in International Business and Finance, Vol.20, pp. 22-44.

Happe, L. N. (1984), South Korea in the Wake of the Oil Price Rise. New York and London: Garlang Publishing.

Hosking, J. (1981), "Fractional Differencing." Biometrika, Vol. 68, pp. 165-176.

Huang, R. D. et al. (1996), "Energy Shocks and Financial Markets." Journal of Futures Markets, Vol. 16, pp. 1-27.

Jawadi, F., Leoni, P. L. (2009), "Threshold Cointegration Relationships Between Oil and Stock Markets." Discussion Papers on Business and Economics No.3.

Jones, C. M., Gautam, K. (1996), "Oil and the Stock Markets." Journal of Finance, Vol. 51, pp. 463-491.

Jones, D. W. et al. (2004), "Oil Price Shocks and the Macro Economy: What has been Learned since 1996?" The Energy Journal, Vol.25, pp. 1-32. 
Jones, M., Kaul, G. (1996), "Oil and the Stock Markets.” The Journal of Finance, Vol. 51, pp. 463-491.

Kwiatkoski, D. et al. (1992), "Testing the Null Hypothesis of Stationarity against the Alternative of a Unit Root: How Sure Are We That Economic Time Series Have a Unit Root?" Journal of Econometrics, Vol. 54, pp. 159-178.

Lardic, S., Mignon, V. (2006), "Oil Prices and Economic Activity: An Asymmetric Cointegration Approach.” Energy Economics, Vol. 34, pp. 3910-3915.

Maghyereh, A. (2004), "Oil Price Shocks and Emerging Stock Markets: A Generalized VAR Approach." International Journal of Applied Econometrics and Quantitative Studies, Vol. 1, pp. 27-40.

Papapetrou, E. (2001), "Oil Price Shocks, Stock Market, Economic Activity and Employment in Greece." Energy Economics, Vol. 23, pp. 511-532.

Park, J., Ratti, R. A. (2008), "Oil Price Shocks and Stock Markets in the US and 13 European Countries." Energy Economics, Vol. 30, pp. 2587-2608.

Robinson, P. M. (1994a), "Efficient Tests of Nonstationary Hypothesis." Journal of the American Statistical Association, Vol. 89, pp. 1420-1437.

Sadorsky, P. (1999), "Oil Price Shocks and Stock Market Activity." Energy Economics, Vol. 21, pp. 449-469. 